659 THE JAPANESE VERSION OF THE WORKPLACE PERMAPROFILER: A VALIDATION STUDY OF THE MEASURE FOR WELL-BEING AT WORK

\begin{abstract}
${ }^{1,2} \mathrm{~K}$ Watanabe*, ${ }^{1} \mathrm{~N}$ Kawakami, ${ }^{3} \mathrm{~T}$ Shiotani, ${ }^{1} \mathrm{H}$ Adachi, ${ }^{3} \mathrm{~K}$ Matsumoto, ${ }^{1} \mathrm{~K}$ Imamura, ${ }^{3} \mathrm{~F}$ Yamagami, ${ }^{3} \mathrm{~K}$ Matsumoto, ${ }^{3} \mathrm{~A}$ Fusejima, ${ }^{3} \mathrm{~T}$ Muraoka, ${ }^{3} \mathrm{~T}$ Kagami, ${ }^{4} \mathrm{~A}$ Shimazu. ${ }^{1}$ Department of Mental Health, Graduate School of Medicine, The University of Tokyo, Tokyo, Japan; ${ }^{2}$ The Japan Society for the Promotion of Science, Tokyo, Japan; ${ }^{3}$ Laboratory of Psychological Sciences, Kanazawa Institute of Technology, Ishikawa, Japan; ${ }^{4}$ Center for Human and Social Sciences, Kitasato University College of Liberal Arts and Sciences, Kanagawa, Japan
\end{abstract}

\subsection{6/oemed-2018-ICOHabstracts. 1670}

Introduction The importance of well-being of workers has recently been recognised, since well-being is protective for mortality, independent of negative factors. Although well-being at work is also discussed intensively, no multi-dimensional measure of well-being at work has been developed in a nonwestern country, such as Japan. The purpose of this study was to investigate the reliability and validity of the Japanese version of the Workplace PERMA-Profiler, which was developed according to a PERMA model, proposed by Seligman (2011) among Japanese workers.

Methods A baseline Internet-based survey was conducted of 310 Japanese workers and part of the respondents (100) were surveyed again at 1 month later. The Workplace PERMA-Profiler (23 items, 3 items per PERMA domain and 8 additional items) was translated according to the international guideline. Job and life satisfaction, work engagement, psychological distress, work-related psychosocial factors, and work performance were also measured for testing the convergent validity. Cronbach's alphas, Intra-class Correlation Coefficients (ICCs), the Standard Error of Measurement (SEM), and the Smallest Detectable Change (SDC) were calculated, and correlational analyses and confirmatory factor analysis were conducted.

Result A total of 310 (baseline) and 86 (follow-up) workers responded and were included for the analyses. Cronbach's alphas and ICCs for scale scores ranged from 0.75 to 0.96 . the SDC of the scale ranged from 1.81 to 2.56. Moreover, the scores of the total and 5 factor scales showed moderateto-strong correlations with job satisfaction, psychological distress, and work-related factors. A 5-factor theory-based model showed not excellent but marginal acceptable fit $(\chi 2(80)$ $=351.30, \quad \mathrm{CFI}=0.892, \quad \mathrm{TLI}=0.858, \quad \mathrm{RMSEA}=0.105$, $\mathrm{SRMR}=0.051)$.

Discussion The Japanese version of the Workplace PERMAProfiler showed acceptable levels of reliability and validity. This measure could be useful to assess well-being at work and promote well-being research among Japanese workers. However, concepts and measures for well-being at work should be investigated in further studies.

\section{PREVALENCE OF GAMBLING IN THE WORKFORCE: A CROSS-SECTIONAL STUDY IN BRITTANY, FRANCE}

\footnotetext{
${ }^{1}$ Matthieu Dezutter, ${ }^{1,2}$ Quentin Durand-Moreau, ${ }^{3}$ Morgane Guillou, ${ }^{4}$ Serge Bouzard,

1,2Jean-Dominique Dewitte. 'Occupational Diseases Centre, University Hospital of Brest, Brest, France; ${ }^{2}$ LABERS EA 3149, University of Brest, Brest, France; ${ }^{3}$ EA SPURBO, University of Brest, Brest, France; ${ }^{4}$ Occupational Health Service, Santé au Travail en Cornouailles, Quimper, France
}

10.1136/oemed-2018-ICOHabstracts. 1671
Introduction To date, very few studies about links between work and addictive disorders concern behavioural addictive disorders such as gambling. Such behaviours may be adaptative strategy for unsatisfied workers. The common physiopathology of addictive disorders allows us to hypothesise that it is possible that such troubles at work could promote gambling. Our aim was to evaluate the prevalence of gambling among workers and its links with work.

Patients and Methods We performed a descriptive cross-sectional monocentric study among all workers who consulted one physician between November 2016 and April 2017, from an occupational health service in Brittany, France. The first step was to ask whether they have gambled during the last year and if it was related to their occupation. The second step was a screening for risky gamblers (using the 'Lie or Bet' questionnaire) among these and then to assess more precisely the severity (using the Indice Canadien du Jeu Excessif, ICJE questionnaire).

Results Among 410 workers who consulted the physician, 138 $(33.7 \%)$ reported gambling during the past year and 12 (2.9\%) considered themselves their gambling experience as related to work. $36(8.8 \%)$ workers were screened as risky gamblers. Among these, the evaluation with the ICJE questionnaire reported $9(2.2 \%)$ workers with no risk, 14 (3.4\%) with a low risk, $13(3.2 \%)$ with a moderate risk and no excessive gamblers.

Discussion Addictive disorders at work are often reduced to the question of substance use disorders, focusing on security aspects. But vulnerability factors are similar to behavioural addictive disorders, including psychosocial risk factors at work. Moreover problem gambling can easily be hidden in a social and professional life. As problem gambling has social repercussions and could be related to work, it should be a topic of interest for occupational health practitioners.

\section{MENTAL STRESSES AND STRAINS IN CONSTRUCTION SECTOR EMPLOYEES}

${ }^{1}$ Wahl-Wachendorf ${ }^{*},{ }^{2}$ Dirk Seidel*, ${ }^{2}$ Thomas Solbach", ${ }^{3}$ Martina Severin-Tölle*. ${ }^{1}$ ASD der $B G B A U$, Berlin, Germany; ${ }^{2} A S D$ der $B G B A U$, Hannover, Germany; ${ }^{3} A S D$ der $B G B A U$, Wuppertal, Germany

\subsection{6/oemed-2018-ICOHabstracts. 1672}

Introduction In 2014, the mental and behavioural disorders diagnosis group accounted for 79 mill. days of incapacity to work and $43 \%$ of retirements due to partial disability (Health and Safety at Work Report 2014). In addition to individual dispositions and serious incidents, stresses in the working environment are other causes considered. Among other things, due to the acceleration of manufacturing and communication processes and increasing mobility requirements, the latter are increasing overall. The BG BAU ASD surveyed employees in the construction sector to find industry-specific approaches to preventing mental stress.

Methods In spring 2016, the BG BAU ASD surveyed 5658 employees in the construction sector nationwide on mental stresses and strains and on their own quality of life as part of routine check-ups. Participation in the survey was voluntary. As the survey was of the construction sector, men accounted for $93 \%$ of participants. Accordingly, only the results of the 